\title{
Effects of cooling on Fe-Ti oxide nanolites crystallisation and melt polymerisation at low pressure and oxidising conditions
}

\author{
FRANCISCO CÁCERES ${ }^{1}$, BETTINA SCHEU ${ }^{1}$, KAI-UWE \\ HESS $^{1}$, CORRADO CIMARELLI ${ }^{1}$, JÉRÉMIE VASSEUR ${ }^{1}$, \\ MELANIE KALIWODA ${ }^{2}$, DONALD B. DINGWELL ${ }^{1}$ \\ ${ }^{1}$ Department of Earth and Environmental Sciences, Ludwig- \\ Maximilians-Universität, Munich, Germany \\ (f.caceres@lmu.de) \\ ${ }^{2}$ Mineral State Collection of Munich, Germany
}

Magma properties, such as viscosity and crystal content, are of crucial importance to understand the behaviour of erupting volcanoes. The bulk viscosity of a magma is largely controled by the viscosity of its melt phase and its crystal load. Magma viscosity exerts a primary control on the eruption style from explosive to effusive. Magmas ascending to shallow levels are exposed to decompression and, to lower extent, cooling. The first leads to volatile loss, which added to cooling, increase melt viscosity and produce nucleation and growth of nano- to milli-metre sized crystals. In order to understand the effect of cooling on the crystallisation process of $\mathrm{Fe}$-Ti oxide nanolites and changes in the melt structure, we conducted magma cooling experiments at highly controlled cooling rates between $0.1-50{ }^{\circ} \mathrm{C} \mathrm{min}^{-1}$. Experiments were conducted in air at atmospheric pressure using an Fe-rich rhyolitic magma at superliquidus starting conditions. We analysed the resultant glasses with a micro-Raman spectrometer to study the structural changes in the silicate melt phase during the transition from a crystal-free melt to a nanolite-bearing magma and the extent of nanolite crystallisation. Raman spectra show that nanolites start forming at cooling rates of $10^{-1}{ }^{\circ} \mathrm{C} \min ^{-1}$ or slower, concomitant with an increase in melt polymerisation. The timescales for nanolites formation are estimated to be in the order of $10^{4} \mathrm{~s}$ for dynamic crystallisation and the same timescales are sufficient for equilibrium crystallisation at stable conditions. Our experimental results at oxidising conditions and slow cooling rates give insights into the formation of Fe-Tioxides nanolites and structural changes of silicate melts in natural volcanic systems. Both, the higher degree of melt polymerisation and the higher load of crystals via nanolite formation can lead to an increase in magma viscosity, further nanolites provide sites for heterogeneous bubble nucleation in degassing magmas, which bears the potential to shift shallow magmas into conditions favourable for an explosive eruption 